\title{
HISTORIC BUILDING INFORMATION MODELLING - ADDING INTELLIGENCE TO LASER AND IMAGE BASED SURVEYS
}

\author{
M Murphy ${ }^{\mathrm{a},}, \mathrm{E} \mathrm{McGovern}^{\mathrm{a}}, \mathrm{S}$ Pavia ${ }^{\mathrm{b}}$ \\ a Dublin Institute of Technology, Bolton Street Campus Dublin 1, Ireland, maurice.murphy@dit.ie \\ a Dublin Institute of Technology, Bolton Street Campus Dublin 1, Ireland, eugene.mcgovern@dit.ie \\ b Trinity College Dublin, Ireland, pavias@tcd.ie
}

Commission V, WG 4

KEY WORDS: CAD, Architectural Modelling, BIM

\begin{abstract}
:
Abstract

Historic Building Information Modelling (HBIM) is a novel prototype library of parametric objects based on historic data and a system of cross platform programmes for mapping parametric objects onto a point cloud and image survey data. The HBIM process begins with remote collection of survey data using a terrestrial laser scanner combined with digital photo modelling. The next stage involves the design and construction of a parametric library of objects, which are based on the manuscripts ranging from Vitruvius to 18th century architectural pattern books. In building parametric objects, the problem of file format and exchange of data has been overcome within the BIM ArchiCAD software platform by using geometric descriptive language (GDL). The plotting of parametric objects onto the laser scan surveys as building components to create or form the entire building is the final stage in the reverse engineering process. The final HBIM product is the creation of full 3D models including detail behind the object's surface concerning its methods of construction and material make-up. The resultant HBIM can automatically create cut sections, details and schedules in addition to the orthographic projections and $3 \mathrm{D}$ models (wire frame or textured).
\end{abstract}

\section{INTRODUCTION}

\subsection{Historic Building Information Modelling (HBIM)}

Historic Building Information Modelling (HBIM) is a novel solution whereby interactive parametric objects representing architectural elements are constructed from historic data, these elements (including detail behind the scan surface) are accurately mapped onto a point cloud or image based survey. The architectural elements are scripted using a Geometric Descriptive Language (GDL). The design and detail for the parametric objects are based on architectural manuscripts ranging from Vitruvius to Palladio to the architectural pattern books of the eighteenth century. The architecture of the renaissance introduced and documented advanced scientific rules for the production of architectural elements, which support the design of parametric models. The use of historic data introduces the opportunity to develop detail behind the object's surface concerning its methods of construction and material make-up. In the final stage of the HBIM process, the prototype libraries of parametric objects are mapped onto the point cloud and image survey data using a system of cross software platform management. Full engineering drawings orthographic, sectional and $3 \mathrm{D}$ models can then be automatically produced from the Historic Building Information Model.

\subsection{Overview of Paper}

In this paper the HBIM process (Murphy, McGovern et al. 2009) is described, section 2 presents a short review of literature concerning parametric modelling and Building Information Modelling. In section 3, the methodology for constructing interactive parametric objects based on historic data is presented; the parametric architectural elements are scripted using a Geometric Descriptive Language GDL. In section 4, an example of mapping the interactive parametric objects onto the laser scan and image survey data is illustrated, resulting in the automation of engineering drawings, demonstrating the complete HBIM process. In conclusion, the evaluation process, which is, now under-way is outlined; initial results indicate the potential for HBIM.

\section{LITERATURE REVIEW}

\subsection{Modelling onto Point Clouds}

The process of mapping vectors onto a $3 \mathrm{D}$ point cloud can be improved by automatically placing primitive $2 \mathrm{D}$ or $3 \mathrm{D}$ shapes onto the point cloud, locating/defining shapes on the point cloud as primitives can achieve this. For example a primitive shape of a cylinder can be mapped onto the point cloud to represent a column, which is then textured from the associated image data (Abmayr, Hortl et al. 2005). An improvement in mapping can be achieved by recognising that buildings are a set of elements, organized by spatial relationships determined by an architectural style or language. The architectural elements can be represented in libraries as parametric objects and mapped onto point cloud or image-based surveys (Dekeyser, Gaspard et al. 2003). In similar work by Deveau et al., primitive objects are mapped onto the scan and image data; these are detected through semi-automatic extraction of the objects where the object localisation is initialised by user interaction. This is then followed by fully automatic segmentation of both the image and 3D data where each object needs to be reconstructed from 
planar surfaces, general geometric primitives and generalised cylinders. When these models do not fit with the surface, triangulation is performed similar to laser data editing software (Deveau, Paparoditis et al. 2005). A classical column is made up of a cylindrical shaft to one third of its height and a tapering shaft for the remainder of the shaft; this subtlety may not usually be detected by automatic or semi-automatic recognition of primitives. Parametric libraries of architectural elements or objects can be built with precision for mapping onto different survey data sets if they are based on architectural language and vocabularies. In their work (Chevrier, Maillard et al. 2009), state that "only simple geometrical shapes are automatically adjusted to cloud points" and only visible parts of the objects can be modelled and rebuilt. Hidden parts are often predictable and can be created as parametric objects based on historic architectural data. Historic architectural and geometrical knowledge is required to create architectural elements.

\subsection{Parametric modelling-Building Information Modelling}

The basic parameters, which describe vector objects, are shape and volume and can be simply expressed as coordinate points and their orientation as an angular value within a $3 \mathrm{D}$ space. The specification for the materials and texture can accompany the numerical data. The 3D object as a parametric model can be edited to revise any or all of its parameters of construction, texture and orientation (CSA 2005 ). Parametric CAD differs from generic $3 \mathrm{D} \mathrm{CAD}$, as parameters are assigned to an object prior to its use. For example, AutoCAD is an a $\mathrm{C}++$ written object-oriented program, the objects which are used to create the lines, arcs, and dimensions that in turn create architectural elements which are not parametric. These objects exist as graphic entities but they do not have intelligence (Ibrahim, Krawczyk et al. 2003). Shah and Mantyla describe parametric modelling as systems which solve object constraints by applying sequential commands to model variables such as geometry, shape, surface texture or feature (Shah and Mäntylä 1995). Architectural elements are represented as real world entities by capturing their characteristics, function and performance under different conditions. The parametric objects can be adaptive to wider architectural scenarios reducing their level of detail or alternatively capture specific knowledge reducing their wider use (Garba and Hassanain 2004).

Other strategic evolutionary stages of 3D CAD are Boundary Representation (B-rep) and Constructive Solid Geometry (CSG) these were both developed in the 1970s and 1980s; Boundary Representation (B-rep) provides details of an object's shape by describing the object's faces, edges and vertices and their relationships. Constructive Solid Geometry (CSG) represents objects using primitive shapes and subsequently combines these in $3 \mathrm{D}$ spaces using Boolean operations to create additional objects. These are low-level operations and abstract in terms of a designer's requirements, a further evolutionary stage introduced the concept of describing the features and characteristics of an object. Feature based CAD can refer to geometry, specification of materials etc., in addition to function which describes the objects role (e.g. wall, door, window etc.) and performance which indicates how elements relate to each other; the window can cut an opening in a wall (Van Leeuwen 1999).

Feature based CAD enables the modification and variation of parameters by the user, the incorporation of object features (such as openings in elements) and interactions between elements within a spatial environment (Van Leeuwen, Wagter et al. August, 1996). In architectural modelling, this is now described as Building Information Modelling (BIM) and differentiates itself as an object intelligent architectural CAD tool rather than a drafting tool. BIM can be described as the assembling of parametric objects within a virtual environment, these objects which represent building components are then used to create or form an entire building. The parametric building objects are not defined singularly but as systems using interaction with other objects and their own values (shape, texture etc.) within a BIM. Objects are described according to parameters some of which are user defined and others, which relate to position in a $3 \mathrm{D}$ environment relative to other shape objects (Eastman 2006). The visualisation of objects is achieved through viewing 2D and 3D features, plans, sections, elevations and $3 \mathrm{D}$ views. BIM can automatically create cut sections, details and schedules in addition to orthographic projections and 3D models (wire frame or textured and animated). "Where traditional CAD primarily focuses on drafting and modelling, BIM specifically uses building semantics including both physical and conceptual elements, such as walls and floors, spaces and activities" (Boeykens and Neuckermans). The evolutionary stages of architectural CAD have moved from $2 \mathrm{D}$ graphic computer representation to parametric modelling to $\mathrm{nD}$ modelling (Tse, Wong et al. 2005 ), and on to feature extraction and finally more recently to Building Information Modelling, as described in figure 1 below.

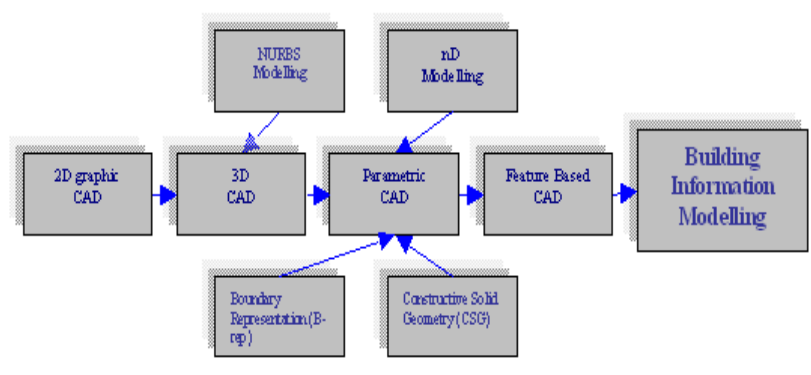

Figure 1 Evolution of BIM

The leading BIM software platforms are Autodesk Revit, GraphiSoft ArchiCAD and Bentley Architecture. ArchiCAD (Graphisoft 2011), is an architectural design application, built around the BIM concept as a standalone application. In ArchiCAD the modelling of objects can be achieved through using standard parametric construction elements. These elements are embedded in the software (such as walls, columns, beams, slabs, roofs etc.) or created as new objects using the embedded scripting language Geometric Descriptive Language GDL. The use of GDL allows for the creation of any number of rich parametric BIM objects and for their storage in internal libraries or data bases for further reuse or modification (Tse, Wong et al. 2005 ). Revit (Autodesk 2011) is also a BIM modelling platform, where the user constructs a mass model with a combination of solid forms and void forms. The faces of the mass volume can be turned into building elements and floors 
and other architectural elements can be generated inside the mass model (Boeykens and Neuckermans). Bentley differs from Archi-CAD and Revit in that it exists as a plug-in for other Bentley platforms.

\section{BUILDING A LIBRARY OF PARAMETRIC OBJECTS}

\subsection{Sources for Design of Parametric Objects - Historic Architectural Data}

In documenting the classical orders, renaissance architects formulated a language whereby the rules, which govern the distribution and combination of parts, resulted in a grammar of ornament and composition. The elements (mouldings, profiles, symbols etc.) become the architectural vocabulary, the whole composition relates to a linguistic structure. This linguistic analogy gave architecture a basis for criticism and understanding (Clarke and Crossley 2000). More recently, linguistics is used for representation and semantics in the field of computing for procedural modelling of buildings and virtual environments. Shape grammar which captures architectural styles can automatically reconstruct these styles in a virtual environment (Ibrahim and Krawczyk 2004). Shape grammar modelling contrasts with using an architectural language to build parametric objects, these objects are then plotted onto laser/image surveys to build a model, the former is automatic and the later depends on human interaction. In this paper, the analysis for modelling of architecture is confined to the classical period in the 17th and 18th centuries in Ireland and Europe. The classical architecture of this period is based on ordered components, geometric proportion and a limited range of material and texture and is an ideal subject for the building of parametric components for virtual models.

Data concerning the historic construction techniques and architectural details can be found in architectural manuscripts, which have evolved, from Vitruvius to the 18th century Architectural Pattern Books. The most important classical source for architecture is the treatise De architectura by Vitruvius, his treatise was possibly written before $27 \mathrm{BC}$, and during the first century AD. The text survived in various manuscripts during the middle ages. Marcus Vitruvius Pollio was a Roman architect working in the reign of the Emperor Augustus; Vitruvius observed design and geometry in ancient architecture of Rome and Greece and documented the classical orders, proportions, methods of construction and materials. Classical architecture was revived during the renaissance, introducing new and more scientific rules for the interpretation of Roman and Greek buildings and also for the production of drawings and surveys. Alberti, published De re aedificatoria (On the Art of Building) in 1452 as an attempt to interpret the work of Vitruvius and improve its philosophical and intellectual content. There were no illustrations included in the original and it was written in Latin. At the same time, Marini, published his interpretations of Vitruvius, unlike Alberti it contained illustrations, presenting the laws of classical proportion. In 1537, Sebastiano Serlio published Regole generali d'architettura (General Rules of Architecture). In 1562 Vignola published his Regola Delli Cinque Ordini D'architettura (The Five Orders of Architecture) which was mainly illustration and lacked text, resulting in a more practical aid for building. His illustrations concentrated on the five orders introducing a new method for setting up the proportions. Andrea Palladio's 1570 work Quattro Libri dell'Architettura (The Four Books of Architecture) also documented a succinct account of the rules of classical architecture, but his treatise which set out full design for buildings (in plan, elevation and section), influenced greatly architecture in Europe and later its colonies (Jokilehto 1986), (Evers B. and Thoenes C. 2003 ), (Fletcher 1901), (Chitham 2005), (Palladio 2002).

The 17th century in Europe witnessed the dissemination of the work of the renaissance masters across Europe with the involvement of scientists and philosophers. In Britain Henry Wotton published the Elements of Architecture in 1624 as an investigation of Vitruvius work; he advocated that empirical rules should regulate systems of architecture, which was reiterated by his contemporary Francis Bacon (1561-1626) who stated that building are not constructed for beauty alone but for commodity, therefore architecture should be examined on the basis of utility (Mallgrave 2005), (Kruft 1994). In addition Perrault (1613-1688) proposed in his treatise on the five orders of columns in architecture (1683) that society could decide what represented beauty and an aesthetic, not a formula of rules for correct proportioning and design of buildings (Evers, Thoenes et al. 2003). A broader interest in classical architecture, which emerged from the enlightenment period, resulted in the involvement of a wider group of architects, intellectual owners, master builders and craftsmen. In the 18th and 19th centuries, architectural pattern books were written and devised by both architects, builders and theoreticians and were widely available in Europe and its colonies. The rules of the Renaissance Architects were more comprehensively documented in Vernacular 18th Century Pattern books which are specific to European and colonial regions. Architectural pattern books are a record of local design; these books contained the historic construction techniques used in the 18th century such as: geometry and principles of the external and internal structure and fabric construction; positioning of openings; proportional relationship of the building's elements; and classical detailing. The first detail in figure 2 below is from Langley's pattern book showing details of a Tuscan column and entablature (Langley 1756), the second (Pain 1792) details an Ionic and Doric capitol and entablature (Pain 1788), the third drawing represents a Doric capitol from the Five Orders of Architecture, the Casting of Shadows based on the system of Vignola (EsquiÃ 1923).

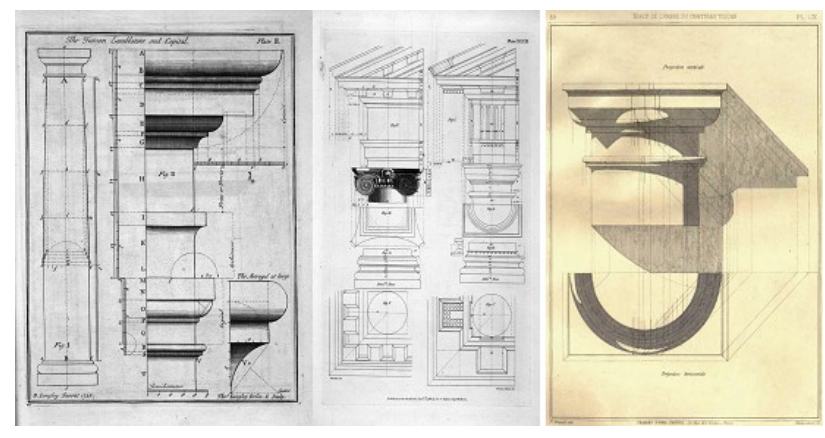

Figure 2 Example of pattern books

\subsection{Building Architectural Elements Using Geometric Descriptive Language}

Geometric Descriptive Language (GDL), is an open script based language embedded in Graphisoft ArchiCAD. ArchiCAD software divides parametric objects into built construction 
elements (walls, columns, beams etc) and GDL objects. GDL provides access to modelling of objects through a BASIC-like language; these objects are specifically constructed for one or many uses and carry the required parametric information for the object's function. All GDL objects are created within a three dimensional space, this space is measured by the $\mathrm{x}, \mathrm{y}$, and $\mathrm{z}$ axes the origin of which is called the global origin $(0,0,0)$. The global origin and local coordinate system prepares the position, orientation and scale of objects, marking positions of objects or shapes which can be moved on the $\mathrm{x}, \mathrm{y}, \mathrm{z}$ axis. The local coordinate system can be moved and provides a reference to the current point of an object with reference to the global origin. Shapes are scripted, based on primitives that represent the simplest solid objects; these are the building blocks of GDL and culminate to create the more complex parts, which are stored in libraries. The set of allowable primitives is limited by the software package. The primitives are stored in the computer memory in binary format, and the $3 \mathrm{D}$ engine generates them within 3D space. The primitives are made up of all the vertices of the object's components, all the edges linking the vertices and all the surface polygons within the edges. The primitives are formed together in groups known as bodies; these bodies make up the 3D model. For shapes that become more complicated and for transformations, which are more abstract, additional values are required in their definition, which may not be found in simple primitives. GDL also includes Boolean operations, Meshing, NURBS and shape commands for creating organic and non-uniform 3D shapes.

Building a library part - Classical Orders

Classical proportioning consists of a series of modular relationships, which are based on the diameter of the base of the column, which represents a single module. Vignola's manuscripts, which concentrated on the five orders, introduced additional and more precise methods for setting up classical proportions. He did this by dividing the order into a ratio of the pedestal, column and entablature as opposed to determining the height of the order based on the diameter of the column alone. Using these ratios for the larger elements reduced the complexity of calculations that arose if the whole building was related to the diameter of the base of a column. The subrelationships between the column and details such as mouldings were devised using 60 divisions of minutes, which represented the diameter of the base of the column as a single module (Ware 1994) (Evers, Thoenes et al. 2003).

The rules of the Renaissance Architects were more comprehensively documented in Vernacular 18th Century Pattern books. Figure 3, detail 1 is an illustration from Pain's 18 th century which gives a description of the geometry of the Doric column capitol and the modular arrangement of the base of the column, dividing it into 60 units (Pain 1792). The systems of proportioning used in the pattern books had different interpretations, which depended on the level of detail given by the author or the knowledge of the author. In detail 2, from the 19th century; fractions are introduced to replace 60 divisions; this approach is much simpler for calculation of minute detail. In the 20th century publication, Robert Chitham introduced metric divisions for the main elements, using four scales A, B, $\mathrm{C}$ and D. Scale A represents the main elements (pedestal, column and entablature etc.) ascending and descending from the underside of the column plinth, but further subdivided into tenths of the column diameter. Scale B shows the proportions of the principal divisions and subdivisions of the order. Scale C shows the proportions of the minor subdivisions, and scale D repeats these in running or cumulative figures.
A Doric column is represented in figure 4 using simple primitives, which are described by their geometric shape and accompanied by a value. In the figure below, the column is made up of simple primitives; Bock, Ellipse, Sphere, Cylinder and Cone followed by a numeric value or parameter that dictates their dimensions. Using Coordinate transformations, the primitives are stacked on the Z-axis or alternatively moved on the $\mathrm{x}$ and $\mathrm{y}$-axis. The block represents the base of the column a cylinder and cone are added on the $\mathrm{z}$-axis to represent the column shaft (the cone represents the tapering of the column one third up the shaft) mouldings are represented through the combination of cylinders and ellipses. These primitives are combined into compound object in this case a Doric column, additional transformations can rescale the subsequent shapes or rotate the object around any of its axis.

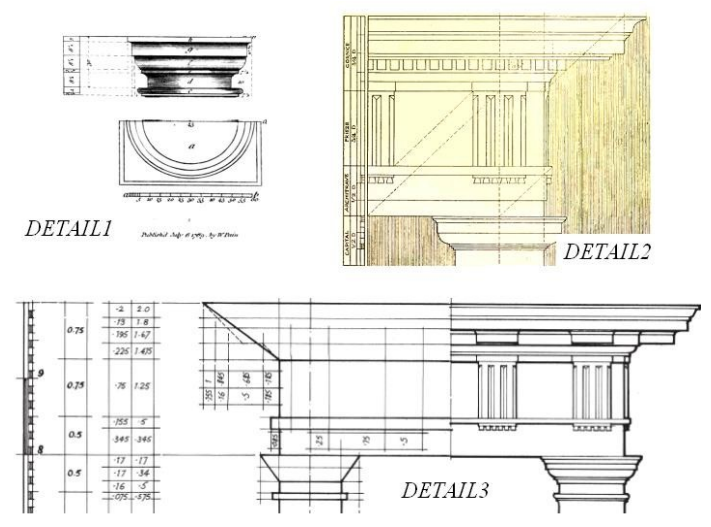

Figure 3 Doric Details from Pattern Books

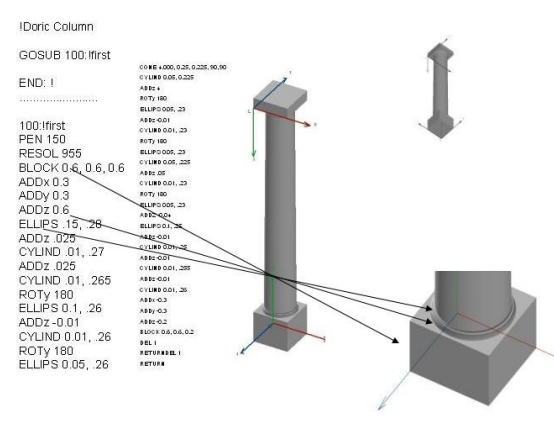

Figure 4 Simple Doric Columns

Procedures, which are required for shapes that are more complicated and for transformations, which are more abstract, may not be found in the use of simple primitives. Illustrated in figure 5 are (a) an astragal and (b) a base mould, which are two of the mouldings that make up the Doric column. These profiles 
are created by lathing or revolving of the objects profile around their centre point, the $2 \mathrm{D}$ profile of the objects are represented on the $\mathrm{x}$ and $\mathrm{y}$ axis and then revolved 360 degrees. Decorated architraves, which are more intricate to model, require commands that are more complex. The profiling is achieved using 2D prism shapes, which are given depth or sent on linear paths (see figure 5c)). In figure 5(d), the components are brought together by stacking on the Z-axis or alternatively moved on the $\mathrm{x}$ and $\mathrm{y}$-axis. If similar or variations of $\mathrm{a}$ component or object already exist in a library or database, the use of flow control in GDL allows for calling or the creation of sub-routines to introduce these objects. Solid geometry objects such as cornices, architraves, mouldings, columns etc. are defined parametrically by combining primitive shapes, or combined with shapes created using GDL commands for lathing or sending $2 \mathrm{D}$ profiles on paths.
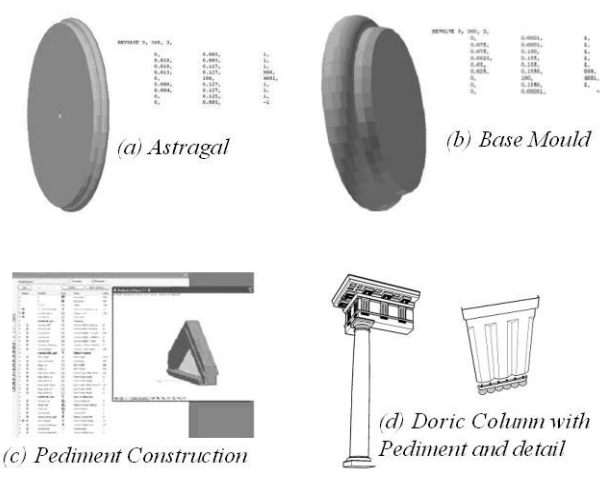

Figure 5 Doric Details

Organic shapes such as the Corinthian capitol require more complex design based on NURBS, meshing and Boolean operations. The Acanthus leaf in figure 6 was formed using NURBS to build a 2D profile and meshing was then used to add the irregular depth of the leaf. Boolean operations were used to create the bend in the leaf around the column; the bend at the top of the leaf was constructed using a shape command and introduce as a separate part of the leaf. It is not possible to bend an object in two directions.
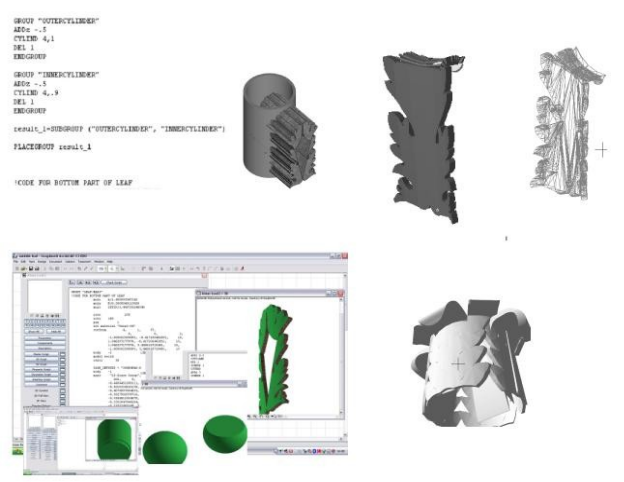

Figure 6 Corinthian Capitol based on NURBS, Meshing and Boolean Operations

Parameters such as geometry, texture, pen and features are used to replace fixed numeric values with variable names, making the object more flexible. These variables are accessible from the library part's settings dialog box while working on the project within the ArchiCAD software. These repetitive parts can be stored as existing library parts for use to make up an object part or entity.

\section{PLOTTING PARAMETRIC OBJECTS ONTO LASER AND IMAGE-BASED SURVEY}

Mapping parametric vector objects on to the point cloud can overcome the slow task of plotting and locating every vector onto the cloud surface. Parametric objects can also introduce the opportunity to develop detail behind the object's surface concerning its methods of construction and material make-up. Within Historic Building Information Modelling, the library of parametric objects is designed as a plug-in for existing Modelling Platforms with the addition of a set of procedures and a framework for mapping these objects onto point clouds and image-based surveys. When a library part or parametric object is placed into the HBIM, it is placed as an icon in 2D in the floor plan position (separated by height or formation levels) and determined along the $\mathrm{x}, \mathrm{y}$-axis and in section and in elevation, on the z-axis. The library objects are not plotted directly in 3D environments, with the result that the objects are not lifted and placed within the $3 \mathrm{D}$ point cloud. The point cloud is segmented to supply floor plans, elevations and sectional cuts as a map for location of library objects. Further interrogation of the point cloud supplies numeric values for formation values (for z-axis location) and parametric values for the library objects themselves, these are recorded in data sheets. Objects are also positioned onto the orthographic image in elevation and adjusted in side elevation and section for angular displacement. In figure 7, part of the process for mapping objects onto point clouds and image-based surveys is illustrated also a sample of automated drawings are included.
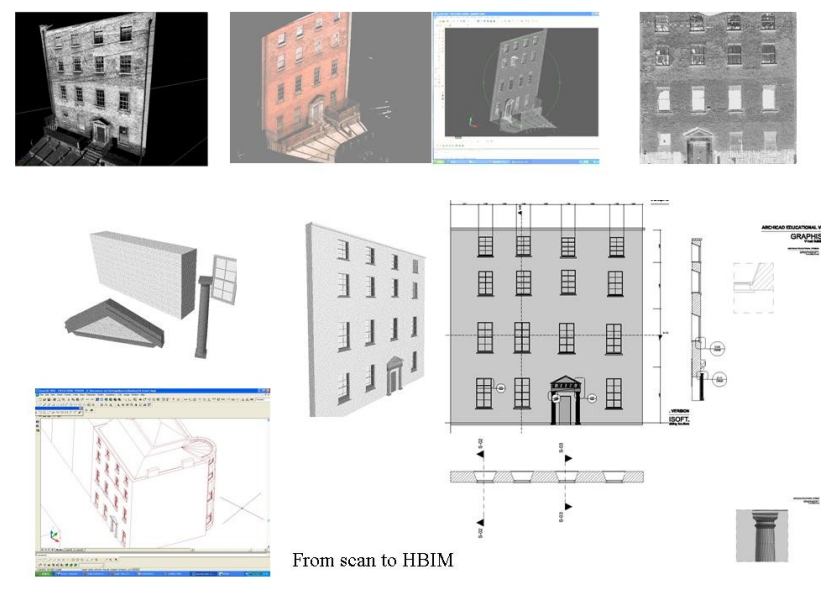

Figure 7 Mapping Objects onto Survey Data - Automated Engineering Drawings

The position of elements in the co-ordinate system relative to other objects is located by mapping directly onto segmented point cloud plan and section; the elements are mapped into position in elevation onto the ortho-image. The dimensions and co-ordinates of the wall, openings and elements are calculated from the point cloud and ortho-image survey and transferred into data sheets. Before placing a construction element, or GDL object, in a HBIM, the default parameters can be edited, 
changing the parameters of shape, size or other properties to correspond with the survey data. The format and sources of data for modelling and mapping the façade wall is detailed in table 1 below.

\begin{tabular}{|c|c|c|c|c|}
\hline \multirow[t]{2}{*}{ Element - Front Façade Wall } & \multicolumn{3}{|c|}{ Data Sources for Measurements/Parameters } & \multirow[b]{2}{*}{ Other Data } \\
\hline & Point Qoud & Data She et & Otho-image & \\
\hline $\begin{array}{l}\text { Volume (height, width and } \\
\text { lergth) }\end{array}$ & $\begin{array}{l}\text { Segmented } \\
\text { Plan }\end{array}$ & $\begin{array}{l}\text { Formation } \\
\text { Level }\end{array}$ & $N A$ & $\begin{array}{l}\text { Ground truths } \\
\text { Exising data }\end{array}$ \\
\hline $\begin{array}{l}\text { Position in the co-ordirate } \\
\text { system relative to otherobjects, }\end{array}$ & $\begin{array}{l}\text { Segmented } \\
\text { Plansisection }\end{array}$ & $\begin{array}{l}\text { Formation } \\
\text { Level }\end{array}$ & $\begin{array}{l}\text { Position on } \\
\text { Elention }\end{array}$ & $\begin{array}{l}\text { Ground truths } \\
\text { Exising data }\end{array}$ \\
\hline $\begin{array}{l}\text { Mateials and techuiqus that } \\
\text { make up the wall's corstruxtion }\end{array}$ & $\begin{array}{l}\text { Sennuted } \\
\text { Elev./section }\end{array}$ & $N A$ & $\begin{array}{l}\text { Mnare and } \\
\text { Textures }\end{array}$ & $\begin{array}{l}\text { Fistoric data and } \\
\text { Library objects }\end{array}$ \\
\hline $\begin{array}{l}\text { Pcsition of (floors) and } \\
\text { firishire level (roof) } \\
\text { Wall operirgs }\end{array}$ & $\begin{array}{l}\text { Segmented } \\
\text { Plansisection } \\
\text { Segmented } \\
\text { Plans/Section }\end{array}$ & $\begin{array}{l}\text { Formation } \\
\text { Level } \\
\text { Formation } \\
\text { Level }\end{array}$ & $\begin{array}{l}\text { Elendion on } \\
\text { image } \\
\text { Elention on } \\
\text { imagg }\end{array}$ & $\begin{array}{l}\text { Ground truths } \\
\text { Exising data } \\
\text { Ground truths } \\
\text { Exising data }\end{array}$ \\
\hline
\end{tabular}

Table 1 Data Sources for Modelling Façade Wall

\section{CONCLUSION}

\subsection{Evaluation}

An evaluation process for HBIM is now under-way, it is intended that this process will meet international and national standards for surveying and recording of historic structures. The prototype is now being tested and evaluated through a number of end user conservation scenarios; an expert group identified these scenarios. From this, a series of historic building case studies, have been identified; a range of HBIM case studies are illustrated in figure 9. Subsequent to the establishing conservation scenarios, end user groups are now testing HBIM, establishing its relevance, ease of use, improvements etc. Modelling accuracy depends on requirements such as level of detail; a sample of live survey data will be utilised as ground truths to evaluate the accuracy of the mapped parametric data both as individual models and integrated models. Mapped detail behind the surface of the structure, which is based on historic detail, will be compared for accuracy with existing survey data of the surveyed structure where detail is available from previously carried out destructive surveys and openings of buildings.

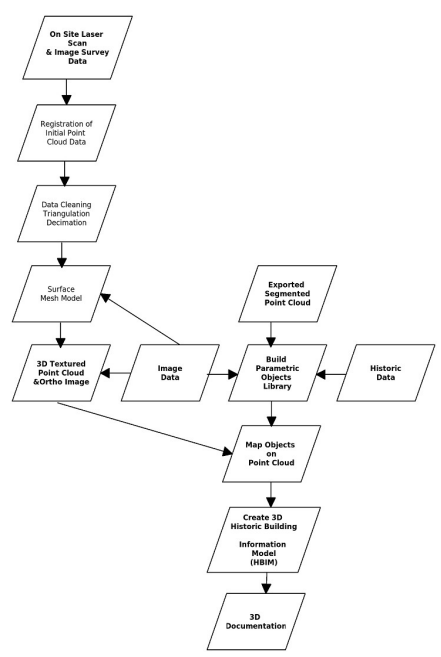

Figure 8 HBIM Process

\subsection{Historic Building Information Model HBIM -}

Finally, the flow chart in figure 8, details the proposed new methodology for HBIM for historic structures and environments. This process involves the following stages: collection and processing of laser/image survey data; identifying historic detail from architectural pattern books; building of parametric historic components/objects; correlation and mapping of parametric objects onto scan data and the final production of engineering survey drawings. The product is the creation of full 3D models including detail behind the object's surface concerning its methods of construction and material make up adding intelligent data to the point cloud and image based surveys. In addition, the HBIM automatically produces full engineering drawings for the conservation of historic structure and environments; this includes 3D documentation, orthographic projections, sections, details and schedules (energy, cost decay etc.), adding intelligence to point cloud data.

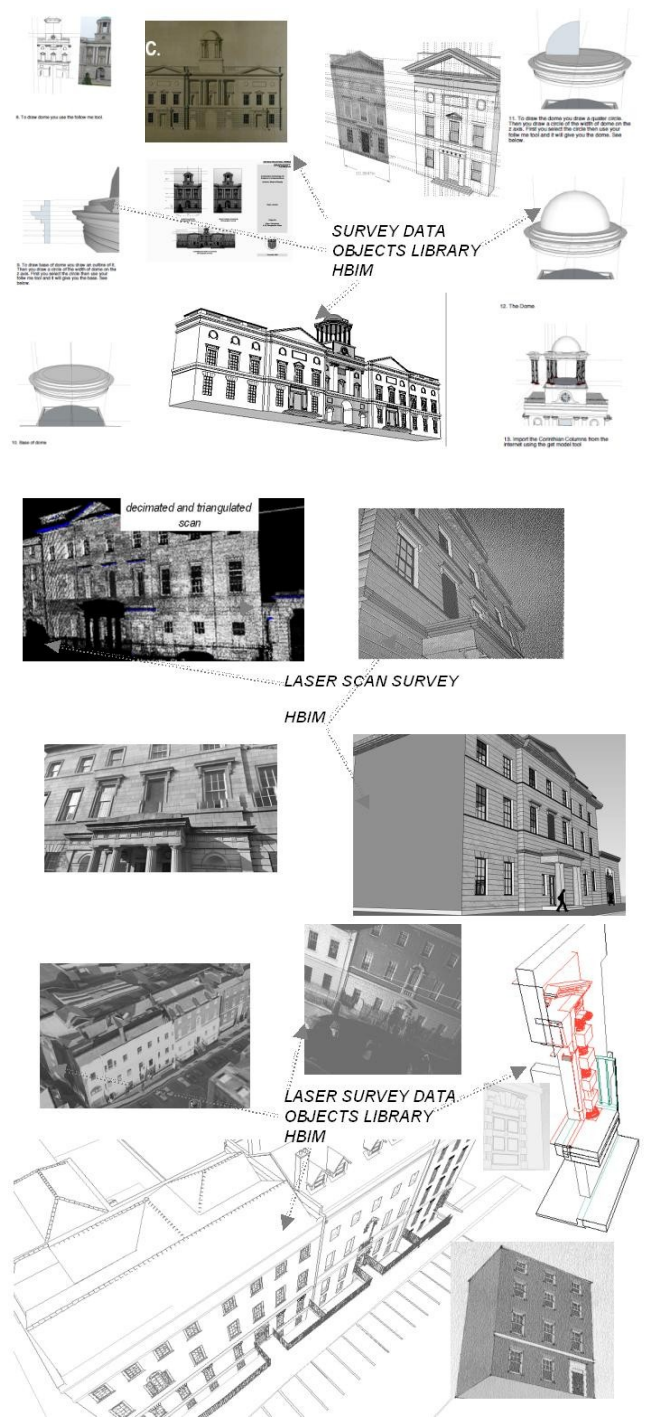

Figure 9 HBIM Case Studies 


\section{References}

Abmayr, T., F. Hortl, et al. ( 2005). Terrestrial laser scanning applications in cultural heritage conservation and civil engineering. Proceedings of the ISPRS working group $\mathrm{v} / 4$ workshop 3d-arch 2005: "virtual reconstruction and visualization of complex architectures", Mestre-Venice, Italy, International Archives of Photogrammetry, Remote Sensing and Spatial Information Sciences.

Autodesk. (2011). "Revit ", from www.autodesk.com/revit.

Boeykens, S. and H. Neuckermans. 2010. "Scale Level and Design Phase Transitions in a Digital Building Model." from http://www.asro.kuleuven.be/IDEA.

Chevrier, C., Y. Maillard, et al. (2009). A method for the 3d modelling of historic monuments: the case of a gothic abbey. Proceedings of the 3rd ISPRS International Workshop 3DARCH 2009:"3D Virtual Reconstruction and Visualization of Complex Architectures" Trento, Italy, International Archives of Photogrammetry, Remote Sensing and Spatial Information Sciences

Chitham, R. (2005). The classical orders of architecture, second edition Oxford, Architectural Press, Elsevier.

Clarke, G. and P. Crossley, Eds. (2000). Architecture and language : constructing identity in European architecture, c. 1000-c. 1650 Cambridge, UK; New York, NY Cambridge University Press.

CSA (2005) "Parametric modelling in AutoCAD ${ }^{\circledR}$-- almost,." CSA Newsletter Volume, DOI:

Dekeyser, F., F. Gaspard, et al. (2003). Cultural heritage recording with laser scanning, computer vision and exploitation of architectural rules. Vision techniques for digital architectural and archaeological archives, Ancona, Italy, The International Archives of the Photogrammetry, Remote Sensing and Spatial Information Sciences.

Deveau, M., N. Paparoditis, et al. (2005). Strategy for the extraction of 3D architectural objects from laser and image data acquired from the same viewpoint. Proceedings of the ISPRS Working Group V/4 Workshop 3D-ARCH 2005: "Virtual Reconstruction and Visualization of Complex Architectures", Mestre-Venice, Italy, International Archives of Photogrammetry, Remote Sensing and Spatial Information Sciences.

Eastman, C. (2006). Report on integrated practice university and industry research in support of BIM. G. I. o. T. American Institute of Architects.

Esquĩ̃, P. (1923). Architecture: the casting of shadows and the first principles of construction based on the system of Vignola : seventy-six plates, W. Helburn.

Evers, B., C. Thoenes, et al. (2003). Architectural theory: from the Renaissance to the present : 89 essays on 117 treatises, Taschen.

Fletcher, B. (1901). A history of architecture on the comparative method for the student, craftsman and amateur, B.T. Batsford.
Garba, S. B. and H. M. Hassanain (2004). A review of object oriented cad potential for building information modelling and life cycle management, 1st ASCAAD International Conference, e-Design in Architecture. KFUPM, Dhahran, Saudi Arabia.

Graphisoft. (2011). from www.graphisoft.com/archicad.

Ibrahim, M. and R. Krawczyk (2004). The Level of Knowledge of CAD Objects within the Building Information Model. CAADRIA 2004 Conference. Seoul, South Korea.

Ibrahim, M., R. Krawczyk, et al. (2003). CAD smart objects: potentials and limitations. ACADIA 2003 Conference. Muncie.

Jokilehto, J. (1986). A history of arhitectural conservation. Institute of Advanced Arhitectural Studies. York, University of York. PhD.

Kruft, H. W. (1994). A history of architectural theory: from Vitruvius to the present, Zwemmer.

Langley, B. (1756). The city and country builder's and workman's treasury of designs, or, The art of drawing and working the ornamental parts of architecture. London, S. Harding.

Mallgrave, H. F. (2005). An Anthology from Vitruvius to 1870, Blackwell.

Murphy, M., E. McGovern, et al. (2009). "Historic building information modelling (HBIM)." Structural Survey Vol. 27 (Iss: 4,): $311-327$.

Pain, W. (1788). Pain's British Palladio, or The builder's general assistant. London: Plate XXXIII.

Pain, W. (1792). The practical house carpenter. London.

Palladio, A. (2002). The Four Books on Architecture. Cambridge, The MIT Press Massachusetts Institute of Technology

Shah, J. J. and M. Mäntylä (1995). Parametric and Featurebased CAD/CAM: Concepts, Techniques, and Applications, Published by Wiley-Interscience.

Tse, T. K., K. A. Wong, et al. (2005 ). "The utilisation of building information models in $\mathrm{nD}$ modelling: A study of data interfacing and adoption barriers." Journal of Information Technology in Construction, ITcon 10.

Van Leeuwen, J. P. (1999). Modelling Architectural Design by Features. Architecture, Building and Planning. Eindhoven, Eindhoven University of Technology. PhD: 286.

Van Leeuwen, J. P., H. Wagter, et al. (August, 1996). Information Modelling for Design Support, a Feature-based approach. 3rd Conference on Design and Decision Support Systems in Architecture and Urban Planning, Spa, Belgium.

Ware, W. R. (1994). The American Vignola: a guide to the making of classical architecture, Dover Publications. 